\title{
Imatinib (STI-571) heals a gastrocutaneous fistula resulting from a malignant gastric stromal tumor
}

\author{
Enders K.W. Ng${ }^{1}$, Simon K.H. Wong ${ }^{1}$, Tony S.K. $\mathrm{MoK}^{2}$, W.Y. Chan ${ }^{3}$, and S.C. Sydney Chung ${ }^{1}$ \\ ${ }^{1}$ Department of Surgery, The Chinese University of Hong Kong, Hong Kong SAR, China \\ ${ }^{2}$ Department of Clinical Oncology, The Chinese University of Hong Kong, Hong Kong SAR, China \\ ${ }^{3}$ Department of Anatomical and Cellular Pathology, The Chinese University of Hong Kong, Hong Kong SAR, China
}

\begin{abstract}
The management of inoperable giant malignant gastrointestinal stromal tumor (GIST) of the stomach used to be a formidable task. We report our success with the use of STI-571 in treating a patient with huge GIST of the stomach complicated by gastrocutaneous fistula after an unsuccessful laparotomy. The patient was a 49-year-old man who presented to our center with a painful epigastric mass in December 2001. Endoscopy, biopsy, and magnetic resonance scan confirmed that it was a malignant stromal tumor arising from the gastric fundus. Laparotomy with an intention to resect the tumor was performed in view of the obstructing symptoms. However, massive bleeding was encountered during dissection of the tumor and gastrectomy was abandoned. The case was further complicated with the development of a gastrocutaneous fistula in the early postoperative period. The patient was then managed with naso-duodenal tube feeding and enteral STI-571 was prescribed. The fistula healed up in 20 days and the mass became impalpable 1 month afterwards. Follow-up computed tonography (CT) scan 3 months later confirmed significant tumor reduction, and the patient has experienced no side effects from the treatment.
\end{abstract}

Key words Stomach $\cdot$ Neoplasm $\cdot$ Stromal tumor $\cdot$ Fistula Therapy

\section{Introduction}

Gastrointestinal stromal tumor (GIST) is an uncommon soft-tissue tumor of the gastrointestinal tract. The stomach is the most common organ involved, and size

Offprint requests to: S.C.S. Chung, Department of Surgery, Prince of Wales Hospital, Shatin, New Territories, Hong Kong SAR, China

Received: October 15, 2002 / Accepted: February 17, 2003 remains the most important predictive factor for its malignant potential [1,2]. As GIST is known to respond poorly to conventional radiotherapy and chemotherapy, surgical extirpation has been the recommended treatment for decades. The prognosis used to be dismal if the tumor was found to be unresectable. Here we report our experience with the use of STI-571, a novel tyrosine kinase inhibitor, in the management of a patient who had a giant malignant GIST of the stomach fistulating to the skin after an unsuccessful exploratory laparotomy.

\section{Case report}

The patient was a 49-year-old man who had been enjoying good past health. He was referred to our institution in December 2001 with a 1-month history of epigastric pain, anorexia, and weight loss. On examination there was a firm and tender mass over the epigastrium. Magnetic resonance scan revealed a huge soft-tissue growth $(17.2 \mathrm{~cm} \times 12.1 \mathrm{~cm} \times 12.3 \mathrm{~cm})$ located in the left upper abdomen, causing downward displacement of the spleen. From the imaging the tumor appeared to be originating from the proximal stomach. Esophagogastro-duodenoscopy confirmed a large bulging lesion at the gastric fundus with a giant central ulceration. Biopsy of the lesion revealed spindle-cell proliferation arranged in short fascicles among a fibro-myxoid stroma, which was highly suggestive of a gastric GIST.

In view of the size of the tumor and the pressure effect, an exploratory laparotomy was performed in early January 2002. During operation the tumor was found to be extremely friable, with extensive vascular infiltration to the surrounding structures, including the left lobe of the liver, retroperitoneal soft tissue, and the left hemi-diaphragm. There were also multiple tumor nodules on the serosal surface of the small intestine. Excision biopsy of these peritoneal lesions was taken. 
However, attempted mobilization of the tumor resulted in massive hemorrhage from the tumor surface. The tumor erupted at a breaking point of the pseudocapsule when it was being dissected off from the diaphragmatic surface. The operation was abandoned because of the excessive hemorrhage. Hemostasis was achieved by argon beam coagulator and packing of the raw surface. The patient was transferred to the intensive care unit afterwards and he gradually recovered.

In the early postoperative period, the patient remained anorexic, with early satiety due to a pressure effect from the unresectable tumor. On day 14 there was foul-smelling fluid discharging from his abdominal wound. Initially it was managed as simple wound infection. Despite antibiotics and optimal dressing care, the wound remained unhealed and food residue was found discharging from it on postoperative day 29. Flexible gastroscopy confirmed that there was a large deep ulceration on the fundal tumor, which might be the internal opening of the gastric fistula. A fine-bore feeding tube was inserted into the proximal jejunum under fluoroscopy and the patient was supported solely by tubefeeding. Oral imatinib mesylate (STI-571; Gleevec; Novartis Pharmaceutical, East Hanover, NJ, USA) was prescribed, at a dosage of $400 \mathrm{mg}$ per day, in late February 2002.

\section{Results}

In the following month, the patient's condition gradually improved and the quantity of discharge from the gastrocutaneous fistula continued to decrease. The initially huge and firm epigastric mass was no longer palpable 1 month after treatment. A water-soluble contrast meal at this time confirmed complete healing of the fistula, despite a residual mass shadow at the gastric fundus. Follow-up computed tomography (CT) scan of the abdomen in late May 2002 showed significant reduction of tumor volume and reappearance of the gastric lumen (Fig. 1A,B). The patient was able to tolerate a normal diet at this time and experienced no significant side effects from the oral imatinib.

Histopathology of the excised peritoneal nodules revealed sheets and trabeculae of spindle cells with ovalto-plump vesicular nuclei and eosinophilic cytoplasm (Fig. 2). Mitoses were counted in up to eight out of ten high-power fields. The tumor cells were positive for CD34 (Fig. 3) and c-kit (Fig. 4), but negative for AE1/3, calretinin, S-100, and desmin by immunohistochemical staining. All these features were consistent with metastases from c-kit-expressing malignant GIST.
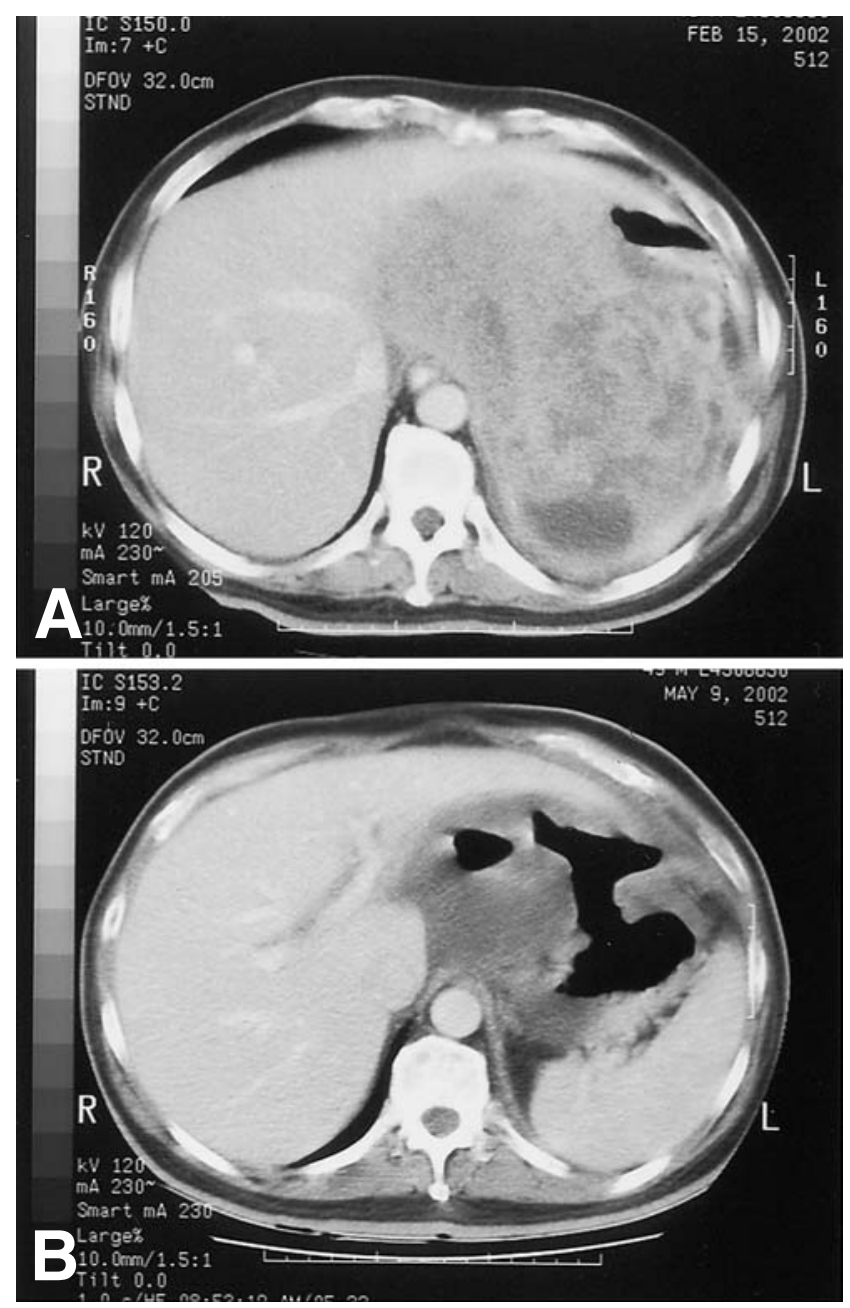

Fig. 1. A Computed tomography (CT) scan of upper abdomen showing the giant gastrointestinal stromal tumor (GIST) in the proximal stomach before the start of imatinib. B CT scan of the same GIST 10 weeks after commencement of imatinib

\section{Discussion}

GISTs are a heterogeneous group of tumors which have previously been termed leiomyomas or leiomyosarcomas. With improved immunohistochemical technology and electron microscopy, it is now clear that GISTs express different histological features, including myogenic properties, neural attributes, or both (mixed GIST) [3,4]. Recently the origin of GISTs has been proposed to be the interstitial cell of Cajal, which is the pacemaker cell of the gastrointestinal system [5].

It is well known that most GISTs express CD34 and the c-kit protooncogene. The protooncogene c-kit encodes a transmembrane tyrosine kinase receptor located on the long arm of chromosome 4 (4q11-q12) [6]. About $60 \%$ of cases of GIST contain mutations in 

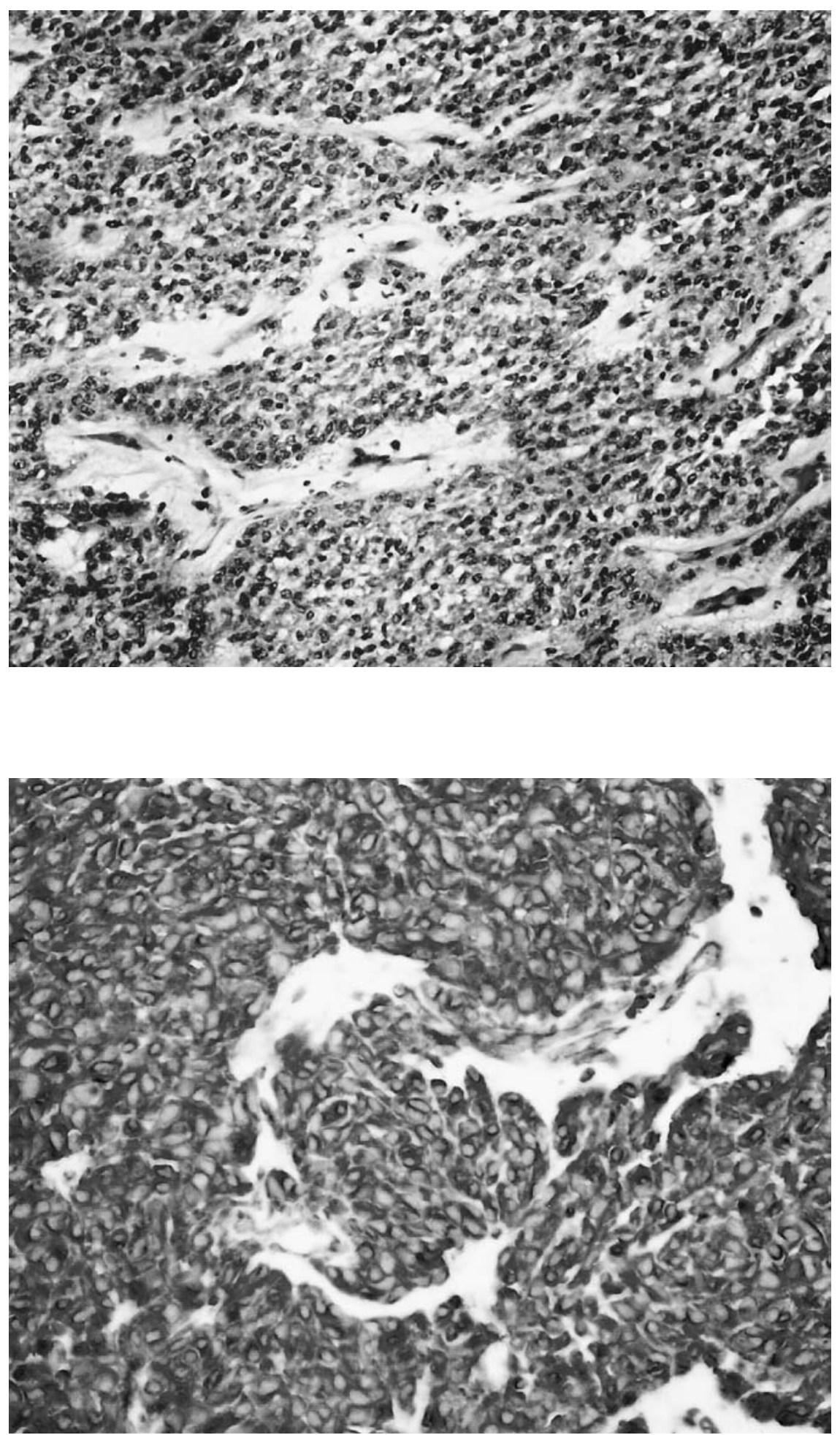

Fig. 2. Peritoneal nodule excised during laparotomy, showing sheets and trabeculae of spindle cells with vesicular nuclei and eosinophilic cytoplasm. H\&E, $\times 200$
Fig. 3. Positive immunostaining for CD34 in the peritoneal nodule. $\times 200$ c-kit at the juxtamembrane domain, which could be either in-frame deletions or point mutations of the exons. These genetic defects cause unprovoked activation of the tyrosine kinase receptor even in the absence of its normal ligand. GISTs with c-kit mutation tend to be of high-grade malignancy, with more frequent metastases and recurrence, as well as early mortality.

Imatinib (STI-571), a novel tyrosine kinase inhibitor, was originally developed for the treatment of chronic myeloid leukemia, based on its inhibitory effect on the 


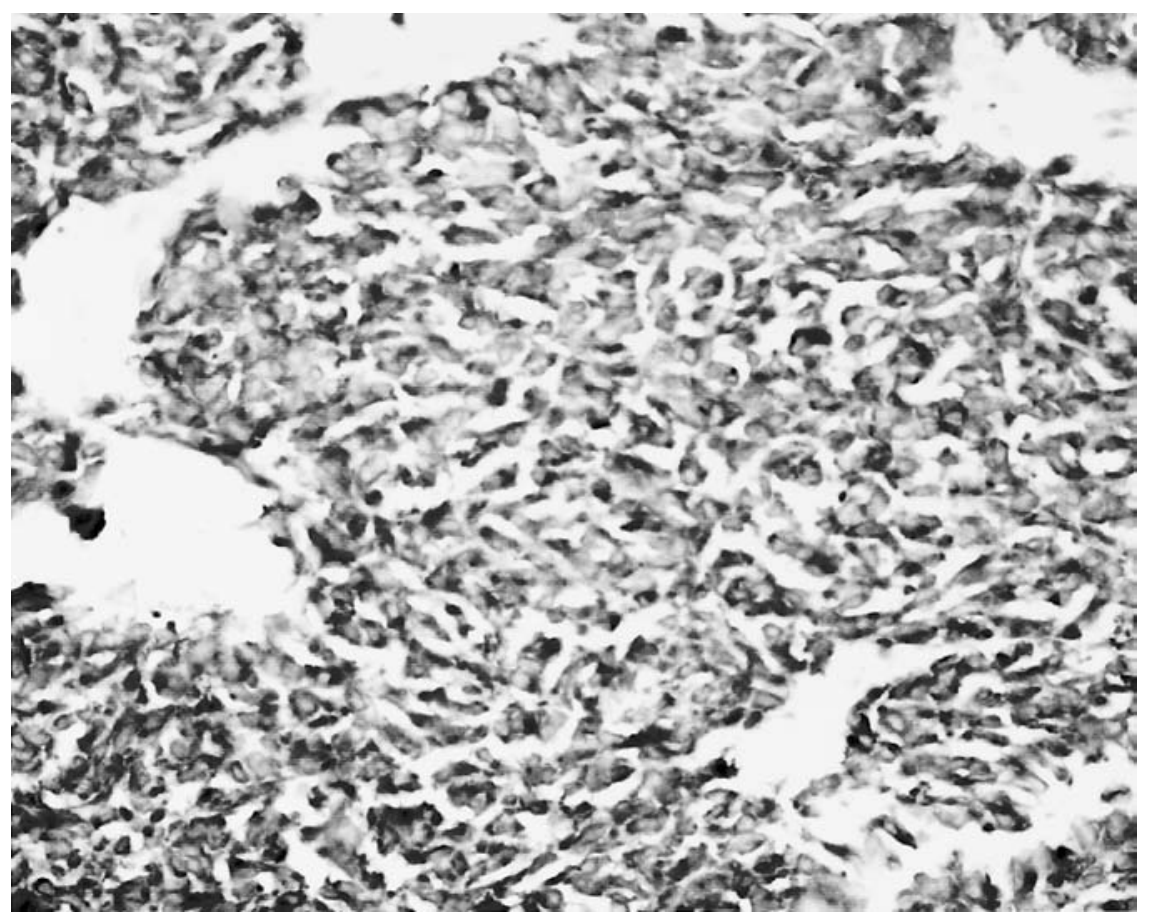

Fig. 4. Positive immunostaining for c-kit in the peritoneal nodule. $\times 200$
BCR-ABL tyrosine kinase [7]. At the same time it was found to have selective inhibitory effect on c-kit, the receptor for stem-cell factor [8]. With its c-kit suppression function, imatinib has recently been tried in patients with inoperable GIST. In a European trial, 32 of 36 patients with GIST had more than 50\% tumor shrinkage after a period of oral imatinib [9]. Similar findings have been reported in an American series, in which 19 of 36 patients with unresectable GIST had significant partial response to the oral treatment [10].

The patient in the present report had a giant GIST arising from the proximal stomach. Neovascularisation around the tumor rendered surgical resection difficult and led to severe blood loss during the attempted dissection. The development of a gastrocutaneous fistula after the unsuccessful laparotomy added further difficulties to the management. Such a fistula would have been expected to be difficult to heal in the past, as it was infiltrated by malignancy. It is noteworthy in the present patient that not only did the tumor have a marked reduction in size but the fistula also sealed off shortly after the administration of imatinib. His condition improved significantly, with regain of body weight, as well as normalization of other nutritional parameters. No side effect has been observed since commencement of the medical therapy. This is the first case of a malignant GIST fistula being successfully healed by imatinib, and underlines the importance of performing immunostaining for c-kit on the tumor specimen. Imatinib should be recommended for patients with unresectable
GIST overexpressing c-kit. Whether the drug can be used as a neoadjuvant therapy to increase resectability of giant malignant GIST warrants further investigation. Currently there is at least one phase III study of the drug in the adjuvant setting, and there is a phase II trial of the drug as neoadjuvant treatment for huge tumor prior to resection.

\section{References}

1. Suster S. Gastrointestinal stromal tumors. Semin Diag Pathol 1996;13:297-313.

2. DeMatteo RP, Lewis JJ, Leung D, Mudan SS, Woodruff JM, Brennan MF. Two hundred gastrointestinal stromal tumors. Ann Surg 2000;231:51-8.

3. Herrera GA, Cerezo L, Jones JE, Sack J, Grizzle WE, Pollack WJ, et al. Gastrointestinal autonomic nerve tumors: "plexosarcoma." Am J Surg Pathol 1989;17:846-53.

4. Lauwers GY, Erlandson RA, Casper ES, Brennan MF, Woodruff JM. Gastrointestinal autonomic nerve tumors. A clinicopathological, immunohistochemical, and ultrastructural study of 12 cases. Am J Surg Pathol 1993;17:887-97.

5. Kindblom LG, Remotti HE, Aldenborg F, Meis-Kindblom JM. Gastrointestinal pacemaker cell tumor (GIPACT): gastrointestinal stromal tumors show phenotypic characteristics of the interstitial cells of Cajal. Am J Pathol 1998;152:1259-69.

6. Hirota S, Isozaki $\mathrm{K}$, Moriyama $\mathrm{Y}$, Hashimoto $\mathrm{K}$, Nishida $\mathrm{T}$, Ishiguro $\mathrm{S}$, et al. Gain of function mutation of c-kit in human gastrointestinal stromal tumors. Science 1998;279:577-80.

7. Buchdunger E, Cioffi CL, Law N, Stover D, Ohno-Jones S, Druker BJ, et al. Abl protein-tyrosine kinase inhibitor STI571 inhibits in vitro signal transduction mediated by c-kit and plateletderived growth factor receptors. J Pharmacol Exp Ther 2000;295: 139-45. 
8. Heinrich MC, Griffith DJ, Druker BJ, Wait CL, Ott KA, Zigler AJ. Inhibition of c-kit receptor tyrosine kinase activity by STI571, a selective tyrosine kinase inhibitor. Blood 2000;96:925-32.

9. van Oosterom AT, Judson I, Verweij J, Stroobants S, Donato di Paola E, Dimitrijevic S, et al. Safety and efficacy of imatinib (STI $571)$ in metastatic gastrointestinal stromal tumors: a phase I study. Lancet 2001;358:1421-3.
10. Demetri GD, von Mehren M, Blanke CD, Van den Abbeele AD, Eisenberg B, Roberts PJ, et al. Efficacy and safety of imatinib mesylate in advanced gastrointestinal stromal tumors. N Engl J Med 2002;347:472-80. 